\title{
DE LOS LIBROS DE ESTILO A LA DIVULGAGIÓN EN PRENSA: SOBRE LOS ACENTOS ANDALUCES Y CANARIOS EN LOS MEDIOS DE COMUNICACIÓN
}

\author{
Susana Guerrero SALAZAR \\ Universidad de Málaga (España)
}

\section{RESUMEN}

Algunos trabajos académicos han demostrado cómo las modalidades andaluzas y canarias han estado tradicionalmente estigmatizadas, por lo que su pronunciación ha estado relegada de los ámbitos formales de los medios de comunicación. El presente artículo tiene dos objetivos. En primer lugar, constatar cuál es la postura de los libros de estilo dirigidos a los medios de comunicación audiovisuales y radiofónicos, esto es, si han venido proscribiendo precisamente algunos de los rasgos fonéticos más característicos de dichas modalidades y si han evolucionado en sus planteamientos en los últimos años; para ello hemos analizado once libros de estilo, publicados desde 1985 hasta 2017. El segundo objetivo es analizar cuál es la percepción que se difunde desde la prensa sobre el uso o no de estas modalidades en los medios de comunicación (tanto nacionales como locales) y si esta se corresponde con los resultados de los estudios académicos; para ello hemos seleccionado los textos de prensa nacional, autonómica y local que se recogen desde 2000 a 2019 bajo la etiqueta «andaluz» y «canario» en la Hemeroteca Virtual de las Lenguas de España (HEVILE) y hemos analizado los 130 que tratan sobre el uso de las modalidades canarias y andaluzas en los medios de comunicación.

Palabras ClaVE: libros de estilo, prensa, medios de comunicación, actitud lingüistica, andaluz, canario.

\section{AbSTRACT}

Some academic works have demonstrated how the Andalusian and Canarian modalities of Spanish have traditionally been stigmatized, so that their pronunciation has been relegated from the formal register(s) of the mass media. This article has two objectives. The first objective is to ascertain the positioning of style books aimed at the audiovisual and radio media to see whether they have been proscribing precisely some of the most characteristic phonetic features of these two regional modalities and whether they have changed their stance on the issue over the last few years. For the purposes os this study, we have analysed eleven style books, published between 1985 and 2017. The second objective is to delve 
into the perception disseminated by the press about whether these modalities should be used in the media (at a national and local level) or not, and whether these is in agreement with the findings of academic studies. To this end, we have selected the national, regional and local press texts collected between 2000 and 2019 under the labels «andaluz» and «canario» in the Hemeroteca Virtual de las Lenguas de España (HEVILE) and we have analysed the 130 texts that deal with the use of the Canarian and Andalusian modalities in the mass media.

KeYWORDS: style books, press, media, linguistic attitude, Andalusian, Canarian.

Fecha de recepción: 08/07/2019

Fecha de aceptación: 18/11/2019

Fecha de la versión definitiva: 18/11/2019

\section{ESTADO DE LA CUESTIÓN}

Distintos estudios sociolingüísticos han demostrado que existen juicios de valor sobre la corrección, la adecuación y la estética de los acentos, los cuales se generan al confundir variedad estándar con correcto, formal, adecuado y estético, y variedad no estándar con incorrecto, informal, inadecuado y antiestético, lo que a su vez conduce a los hablantes, en numerosas ocasiones, a la inseguridad lingüística (Hernández-Campoy 2004: 33). De hecho, hasta hace unos años, para actuar en teatro, cine o cualquier medio de comunicación había que ocultar cualquier tipo de acento que revelara una modalidad lingüística diferente de la norma castellana estándar. Como explica Rodero Antón:

Los locutores radiofónicos han estado obligados a lucir una correcta pronunciación castellana. De manera artificial se ha vuelto a imponer un tipo de pronunciación sobre otra. Por eso, es lógico que en los informativos nacionales se descubra un perfecto y auténtico castellano, puesto que se ha generalizado por obligación. Cualquier locutor con pronunciación meridional ha necesitado aprender a imitar la castellana. Si estas circunstancias no se hubieran producido de esta manera y convivieran ambas pronunciaciones, ningún oyente se mostraría extrañado ante la pronunciación de un locutor, por ejemplo, canario (Rodero Antón 2003: 296-297).

Para Méndez G. ${ }^{a}$ de Paredes, sin embargo, esta situación ha cambiado y los medios actualmente reflejan bastante diversidad:

En efecto, en la actualidad los medios son más que nunca reflejo del uso que hacen los hablantes de su lengua y ofrecen esa realidad variada y diversa que es una lengua histórica, pues transmiten una representación de síntesis social, y al hacerlo, transmiten también una representación de sus actitudes lingüísticas concretas. La consecuencia de esto es que los hablantes de español cada vez están más familiarizados con otras variedades de su 
lengua que, de otro modo, no podrían oír. Adquieren con ello conciencia de su nexo social y enjuician sus variedades de lengua y las de los demás (Méndez G. ${ }^{a}$ de Paredes 2003: 165).

El caso de las variedades andaluzas y canarias resulta de gran interés en este sentido, ya que son formas de hablar español cuya peculiaridad reside fundamentalmente en la pronunciación, pues no presentan, desde el punto de vista gramatical, diferencias de entidad. Además, tanto el español que se habla en Andalucía como el que se habla en el archipiélago canario se caracterizan por una notable diversidad o polimorfismo, por lo que los especialistas prefieren la etiqueta de hablas o modalidades andaluzas o canarias. De hecho, no existe ningún rasgo fonético común ni a todos los hablantes andaluces ni a todos los canarios, ni tampoco ninguno que sea exclusivo de ninguna de estas modalidades. Los rasgos de pronunciación más difundidos en Andalucía son precisamente aquellos en los que coincide con algunas de las otras hablas meridionales, esto es, con el llamado español atlántico (Canarias y América), los cuales resumimos a continuación ${ }^{1}$ :

1) La $s$ predorsoalveolar (frente a la apicoalveolar castellana) y el seseo. Este es un rasgo generalizado en Canarias y América, mientras que en Andalucía solo sesea algo más de un tercio ${ }^{2}$.

2) La aspiración (o incluso pérdida) de la $-s$ implosiva, que constituye un rasgo claramente separador respecto al español central y norteño.

3) La pronunciación relajada o aspirada de la /x/; esta aspiración no se da en el andaluz más oriental, que mantiene la fricativa velar.

4) La pronunciación sonorizada y adherente de la ch, rasgo que está presente en todas las Canarias y en todos los niveles. En Andalucía la $c h$ aflojada y fricativa (en vez de la africada castellana) es un rasgo poco difundido del que el hablante que domina varios registros suele despojarse en situaciones formales ${ }^{3}$.

${ }^{1}$ El resumen está tomado de la página web del grupo de investigación El español hablado en Andalucía, de la Universidad de Sevilla, liderado por Rafael Cano Aguilar (<http://grupo. us.es/ehandalucia/que_es_el_andaluz/01_una_primera_mirada.html $>$ ), cuyas contribuciones al estudio de la modalidad andaluza resultan de gran interés.

${ }^{2}$ La tendencia distinguidora va en aumento en hablantes jóvenes y escolarizados, debido a la influencia del prestigio de la norma del español peninsular, ayudada por su difusión en los medios de comunicación. El ceceo, por el contrario, está en claro descenso, debido a la disminución del analfabetismo y a que posee una consideración social baja. Cfr. nota 1.

${ }^{3}$ Existen otros rasgos que poseen un grado de difusión más reducido, pues aparecen en grupos sociológicos más específicos y, por lo general, carecen de prestigio, como la confusión $-r /-l$ implosivas, la aspiración de la $h$-inicial, la caída de la - $d$-intervocálica, la pérdida de las consonantes finales, etc. En cuanto al yeísmo, es un fenómeno tan ampliamente difundido en el español general, que no podemos considerarlo característico de las modalidades andaluzas o canarias. Cfr. nota 1. 
Las modalidades andaluzas y canarias, además de compartir rasgos de pronunciación, comparten cierta estigmatización histórica, que han puesto de manifiesto algunos trabajos académicos, entre otros, los de Carrascosa Pulido (2002), Carvajal (2002), Jiménez Fernández (2002), Méndez G. ${ }^{a}$ de Paredes (2009), Ureña Rodríguez (2014 y 2015) y León-Castro Gómez (2016), para el andaluz; y los de Trujillo Carreño (1981), Ortega Ojeda (1981), Morera Pérez, (1990), Morgenthaler García (2008) y Ďad’ová (2017), para el canario.

De gran interés resultan los trabajos sociolingüísticos fruto del Proyecto para el estudio de creencias y actitudes hacia variedades de español en el siglo XXI (PRECAVES XXI), coordinado por Cestero Mancera y Paredes García (2015 y 2018), concretamente los que se recogen en el monográfico del Boletín de Filología de la Universidad de Chile (2018), donde se dan a conocer las percepciones de los estudiantes universitarios de distinta procedencia (Madrid, Palma de Mallorca, Sevilla, Granada, Las Palmas de Gran Canaria, Medellín, Santiago de Chile y Buenos Aires) hacia su propia variedad, así como hacia otras variedades cultas del español, concretamente la castellana, la andaluza, la canaria, la mexicana, la caribeña, la andina, la chilena y la rioplatense (Cestero Mancera y Paredes García 2018).

Nos interesan especialmente tres estudios. En primer lugar, el de Hernández Cabrera y Samper Hernández (2018), que muestra que los estudiantes universitarios canarios hacen una valoración directa sobre su variedad bastante positiva. Sin embargo, manifiestan una doble perspectiva sobre el castellano: por un lado, la creencia de que es la mejor variedad y de que sus hablantes gozan de un elevado estatus social; por otro, su consideración negativa a partir de preguntas sobre aspectos cognitivos y afectivos. Según las autoras, estos datos revelan «la importancia de la prueba auditiva de grabaciones representativas de los distintos dialectos como método que permite acceder a una valoración más real de las variedades, más allá de opiniones apriorísticas que en ocasiones se basan en estereotipos culturales» (Hernández Cabrera y Samper Hernández 2018: 206).

En segundo lugar, destacamos el estudio de Santana Marrero (2018) sobre estudiantes sevillanos, quienes revelan una actitud intermedia entre la valoración positiva de su propia modalidad y la idea de que la castellana es mejor. Estas creencias se reflejan tanto en la pronunciación de la calle, como en la de los profesionales de la educación, de los medios de comunicación y de los políticos, en cuyas intervenciones se muestra «una lucha constante entre el apego y el rechazo a lo vernáculo» (Santana Marrero 2018: 143).

En tercer lugar, el trabajo de Manjón-Cabeza Cruz (2018) sobre los universitarios granadinos, que manifiesta que las valoraciones directas de las voces andaluzas tienden a ser positivas, sin embargo, las indirectas son contradictorias, debido, por un lado, «a una visión, quizá tópica, muy positiva 
de la región (bonita, interesante) y sus habitantes (graciosos, agradables, amables)»y, por otro, «a la estigmatización de muchos rasgos lingüísticos andaluces, que llevan a asociar al andaluz con el nivel sociocultural bajo o a degradarlo a la categoría de jerga» (Manjón-Cabeza Cruz 2018: 175).

En cuanto a los estudios que atienden al uso de la modalidad andaluza en los medios de comunicación, en ellos prevalece la idea de que el andaluz es un castellano mal hablado, de ahí que este se oculte en situaciones formales. De hecho, los periodistas sevillanos entrevistados por Díaz Salgado (2002) admitieron que abandonaban los rasgos andaluces cuando estaban ante el micrófono $(45 \%)$ y reconocieron que se habían visto obligados en alguna ocasión a cambiar el acento andaluz por el castellano $(58 \%)^{4}$.

El estudio de León-Castro Gómez (2016) ha vuelto a constatar este hecho. Según la autora, muchos hablantes cultos andaluces y, entre ellos, un gran número de profesionales de la comunicación, entienden que, en determinadas situaciones comunicativas que requieren una cierta formalidad, sus rasgos de pronunciación no resultan válidos, por ello, tienden a adoptar las particularidades fonéticas consideradas prestigiosas, esto es, la variedad «estándar del español centropeninsular o norteño»; sin embargo, un número muy inferior de periodistas se expresa con corrección en un «estandarizado andaluz», esto es, con los rasgos de la modalidad lingüística andaluza cuyo índice de aceptación social es alto (lo que sería la forma de pronunciación más representativa de un andaluz culto). León-Castro (2016: 1598) defiende la idea de que los medios de comunicación, por su influjo indiscutible y su autoridad en la sociedad, conforman una plataforma idónea para proyectar un modelo de pronunciación andaluz basado en todos aquellos rasgos de prestigio, de forma que pueda llegar a considerarse una variante válida frente al modelo norteño, que es el que prima en la televisión.

Con respecto a las modalidades canarias, los trabajos académicos de finales del siglo xx (Trujillo Carreño 1981; Ortega Ojeda 1981; Morera Pérez 1990) pusieron de manifiesto la poca autoestima del hablante canario hacia su variedad, sin embargo, algunos trabajos de comienzos del siglo XxI (Armas Marrón 2002; Morgenthaler García 2008) han mostrado un cambio de actitud que se constata en cuatro ámbitos (Morgenthaler 2008: 217): en el académico (sobre todo con la publicación, a partir de los setenta, de trabajos sobre las hablas canarias, y con la creación de la Academia Canaria de la Lengua en el año $2000^{5}$ ), en el político-institucional, en los hablantes (los cuales valoran la variedad vernácula de manera abierta como positiva y prestigiosa) y, por último, aunque en menor medida, en los medios de

\footnotetext{
${ }^{4}$ Los informantes eran 31 periodistas sevillanos que trabajaban como presentadores o redactores en Canal Sur Televisión.

${ }^{5}$ Fue creada el 21 de diciembre de 1999 e inscrita el 5 de abril de 2000 en el Registro de Fundaciones Canarias.
} 
comunicación. De hecho, al igual que ha sucedido con el andaluz, algunos estudios han demostrado que las modalidades canarias tienen escasa representación en los medios audiovisuales y que aún sigue existiendo un alto grado de inseguridad lingüística de manera encubierta, debido a la conciencia de periferia geográfica que tienen los hablantes canarios y a la falta de una norma de prestigio propia que oriente su actuación lingüística, por lo que algunos consideran la variedad canaria como «inferior, mal hablada o incorrecta» (Morgenthaler 2008: 391).

El trabajo de Ďad'ová (2017) sobre la variación fonética en los informativos de la Televisión Canaria parte del hecho de que las actitudes lingüísticas negativas y la inseguridad lingüística son perceptibles en los medios de comunicación en aquellos hablantes cuya función está directamente relacionada con el mercado lingüístico. Para demostrar esta hipótesis ha analizado las realizaciones de cuatro fonemas de la lengua española en la expresión oral de los presentadores, corresponsales y entrevistados en cinco programas informativos: la $-s$ implosiva (como $-s$, aspiración o pérdida), la jota (velar o aspirada), la $n$ y la $c h$. Una conclusión relevante del estudio es la importancia del mercado lingüístico y del carácter polifónico y planificado del lenguaje de las telenoticias, factores relevantes que influyen en el número elevado de realizaciones estándares en el habla de los presentadores y reporteros canarios ${ }^{6}$. El carácter planificado de la lengua es un factor que proporciona a los locutores mayor oportunidad de elegir la variedad hablada, ya que el contenido de la emisión está previamente preparado y, al emitir, el locutor se centra puramente en la forma y no en el contenido del mensaje, lo cual facilita el optar por la pronunciación septentrional. Por tanto, la frecuencia elevada de realizaciones típicamente canarias en los momentos espontáneos (saludos, agradecimientos, etc.) se puede explicar como efecto de la desviación del discurso planificado.

Como podemos apreciar, todos los estudios empíricos realizados coinciden en que las modalidades andaluzas y canarias apenas están representadas en los contextos formales de los medios de comunicación.

\section{OBjetivos y MEtodología}

El presente artículo tiene dos objetivos. En primer lugar, constatar cuál es la postura de los libros de estilo dirigidos a los medios de comunicación

${ }^{6}$ Los entrevistados se han dividido en dos grupos: el primero engloba a hablantes cuyo estatus socioeconómico es alto (políticos, diputados municipales, alcaldes, portavoces de distintos partidos y expertos en economía, educación, etc.). En el segundo grupo se han reunido los de nivel sociocultural medio o bajo y, además, hablantes cuyo nivel sociocultural se desconoce. 
audiovisuales y radiofónicos, esto es, si han venido proscribiendo precisamente algunos de los rasgos fonéticos más característicos de las modalidades andaluzas y canarias y si han evolucionado en sus planteamientos en los últimos años; para ello hemos analizado once libros de estilo, publicados desde 1985 hasta 2017.

El segundo objetivo es analizar cuál es la percepción que se difunde desde la prensa sobre el uso o no de estas modalidades en los medios de comunicación (tanto nacionales como locales) y si estas se corresponden con los resultados de los estudios académicos que hemos comentado en el estado de la cuestión; para ello hemos realizado un trabajo exploratorio de corte analítico que se centra en un corpus extraído de la Hemeroteca Virtual de las Lenguas de España (HEVILE) ${ }^{7}$, una herramienta digital que recoge noticias de los distintos medios de comunicación, regionales, nacionales e internacionales, relacionadas con temas lingüísticos. Los textos están etiquetados y permiten hacer búsquedas parametrizadas. De este modo, hemos seleccionado los textos de prensa nacional, autonómica y local que se recogen desde 2000 a 2019 bajo la etiqueta «andaluz» (251) y «canario» (136) y hemos analizado los 130 que tratan sobre el uso de las modalidades canarias (42) y andaluzas (88) en los medios de comunicación.

\section{RECOMENDACIONES ORTOLÓGICAS EN LOS LIBROS DE ESTILO}

La Ortología es la gran descuidada en los estudios de Lingüística. La Real Academia Española no ha publicado ninguna obra de referencia a este respecto. Lo más reciente es el capítulo sobre «Pronunciación y elocución» que incluye en su Libro de estilo de la lengua española según la norma panhispánica (Academia Española y ASALE 2018: 211-267), un texto que no se centra en ninguna variedad en particular, sino que es un compendio de recomendaciones básicas y generales para todo el mundo hispánico.

Aunque algunos autores -entre otros Gómez Torrego (2002), Hernán$\operatorname{dez}(1998,2004,2009)$ y Medina Guerra $(2002,2005$ y 2008)- han abordado en sus trabajos algunos aspectos ortológicos, en general, son muy pocos los estudios en este sentido, y, menos aún, que se centren en el español meridional que se utiliza en los medios de comunicación (concretamente el de las modalidades canarias y andaluzas). La razón de esta escasez es,

${ }^{7}$ La hemeroteca virtual es una herramienta creada dentro del portal Lengua y Prensa (<http://www.lenguayprensa.uma.es $>$ ), un proyecto del grupo de investigación HUM 046 Análisis de Noticias sobre Divulgación Lingüística, las Lenguas de España y sus variedades, del que soy miembro. Este artículo se enmarca dentro del convenio específico de colaboración entre la Universidad de La Laguna y la Universidad de Málaga dentro del Proyecto Lengua y Prensa (Ref. 8.07/5.20.5178), del que soy investigadora principal. 
posiblemente, como señala Méndez G. ${ }^{a}$ de Paredes (2009: 267-268), que la norma está asociada al concepto de planificación y normalización, por lo que «no es factible articular una idea de normatividad sin que planee sobre ella el fantasma de la imposición», dado que cualquiera que sea el tipo de norma, va siempre inherentemente acompañada de una relativa prescripción, pues se requiere «una labor técnica (selección de usos o de rasgos de pronunciación) que a la vez es ideológica y política», a lo que se une «la dificultad de establecer, dentro de la realidad española, una norma culta sin equivalencia escrita» ${ }^{8}$.

En cualquier caso, los medios de comunicación se rigen por normas lingüísticas, que, como indica Humberto Hernández (2009: 39), están relacionadas con el concepto de corrección, que no puede ser contrario a los hábitos generalizados, que nunca es el único (como no hay una única norma) y que es variable (como vamos a comprobar en los libros de estilo que analizaremos a continuación). Hernández (1998: 51) es partidario del reconocimiento explícito de dos estándares, dos normas ortológicas, la de la modalidad castellana y la de la meridional (y americana); como también lo son Vaz de Soto (1981, 1995), Garrido Medina (1994), Fontanillo y Riesco (1994) o Tubau (1995), quienes han defendido la cooficialidad del español meridional junto al español septentrional en los medios de comunicación orales.

En los últimos años se han publicado un buen número de libros de estilo para los medios de comunicación ${ }^{9}$, la mayoría de ellos enfocados a la prensa escrita, por lo que está justificado que no tengan en cuenta los aspectos ortológicos. Sin embargo, los manuales de estilo que han surgido al amparo de los medios de comunicación audiovisuales y, sobre todo los radiofónicos, tampoco abordan, como cabría de esperar, cuestiones claves como la locución o el uso expresivo de los componentes del lenguaje propio de la radio, sino que se limitan a proscribir algunos vulgarismos en la pronunciación, el cambio de acentuación o determinadas curvas de entonación. Como ha manifestado Perona Páez (2009: 383), las principales cadenas de radio españolas han venido otorgando más importancia al contenido de las informaciones y a las normas de redacción de las noticias que a su forma de transmisión.

A continuación, vamos a hacer un breve recorrido por once libros de estilo dirigidos a los medios de comunicación (fundamentalmente audiovisuales o radiofónicos), publicados desde 1985 a 2017, completando el trabajo iniciado con anterioridad por Hernández (1998) o Medina Guerra

${ }^{8}$ Para un análisis de este tema véase Carbonero Cano (2011).

${ }^{9}$ Sobre los libros de estilo en lengua castellana elaborados para los medios de comunicación no solo en España, sino también en Hispanoamérica e, incluso, en Estados Unidos, el trabajo más exhaustivo por el esfuerzo de catalogación que hace es el de Rojas Torrijos (2011). 
(2005). Nos centraremos en cómo tratan las cuestiones ortológicas que afectan, de algún modo, a las modalidades andaluzas y canarias.

Comenzaremos por el Manual de español urgente (Agencia EFE 1985), por ser el primero, el más difundido y el que consta de mayor número de ediciones. La primera es de 1985 y la última, la décimo novena, de 2015. Se diferencia de otros manuales, como señala Sánchez Arnosi (1994: 8182), en que tiene en cuenta a toda la comunidad hispanohablante y en que ha sido creado por un equipo heterogéneo formado por filólogos, académicos y profesores de Ciencia de la Información. Aunque tiene como fin prioritario el mantenimiento de la unidad del idioma y defiende el uso del lenguaje «estándar culto de carácter instrumental», es contrario a la neutralización del estilo como sinónimo de insipidez. Las primeras ediciones de este manual no indicaban nada sobre ningún aspecto ortológico; en 1992 se añadieron unas «Notas sobre pronunciación» que se han ido reeditando prácticamente sin ningún cambio; en ellas se decía: «Conviene contribuir al mantenimiento de la diferencia entre la $l l$ y la $y$, pero el yeísmo, o pronunciación de la $l l$ como $y$, dada su gran difusión, no debe considerarse incorrecto» (2008: 55). En la última edición (2015), entre otras cosas, se indica que el seseo es propio de las zonas meridionales, de Canarias y del español de América y que está admitido por la norma culta (no así el ceceo). Del yeísmo dice únicamente que, dada su gran difusión, no debe considerarse incorrecto, omitiéndose la conveniencia al mantenimiento de los dos fonemas que aparecía en ediciones anteriores.

El Libro de estilo de Telemadrid (1993) destaca que «Las faltas contra la correcta pronunciación suelen consistir en articulaciones viciosas de los sonidos, en la mala pronunciación de las sílabas, conocida con el nombre de vulgarismos, y, sobre todo, en abusos de acento, tono y armonía en la pronunciación de las palabras» (Telemadrid 1993: 118). Se recogen entre las pronunciaciones viciosas de los sonidos, sin hacer matización alguna, el yeísmo ( «las personas que hablan para el público -profesores y locutoresdeben distinguir entre las dos pronunciaciones y aplicarlas correctamente») y el seseo/ceceo ( «ambos fenómenos constituyen una transgresión de las normas ortológicas de la Academia y, si suenan, es por incuria o incumplimiento»). Como ya puso de manifiesto Medina Guerra (2005: 100), la inclusión en este manual del yeísmo y del seseo/ceceo junto a pronunciaciones como la velarización de la $h$ ante el diptongo $u e$, la relajación de la - $d$ - intervocálica o la pronunciación de la $-d$ - como $[\theta]$ resulta del todo desacertada, ya que una cosa son los rasgos dialectales (que poseen una localización geográfica precisa) y otra muy distinta los vulgarismos (que aparecen en hablantes de poca cultura de cualquier procedencia).

El Manual de estilo de TVE (Mendieta 1993), a pesar de reconocer «... la importancia de la correcta pronunciación de las palabras en un medio de comunicación hablada, como la televisión» (1993: 114), resuelve las cues- 
tiones relacionadas con la Ortología en tan solo siete páginas, de las cuales cuatro corresponden a la «Relación de palabras de pronunciación dudosa o viciosa». Condena el ceceo, la pronunciación andaluza de la $c h$ como sh, la supresión o el reforzamiento de la $d$ y la confusión $r / l$. Del seseo dice que «solo se considera normal en Andalucía, Canarias y América». Admite el yeísmo como correcto.

Todavía más escuetas son las «Normas de pronunciación y lectura» de la Guía de estilo de Onda Cero Radio (Madero et al. 1996). En esta obra las normas ortológicas se limitan a la enumeración y descripción de los fonemas del español. Las consideraciones en torno a la pronunciación son: evitar el ceceo y el seseo, no pronunciar el sonido correspondiente a la grafía $x$ como /s/, no añadir $-s$ final en las formas verbales de segunda persona del singular del pretérito anterior, no suprimir la $-d$ - intervocálica de los participios acabados en -ado (pp. 82-83). Lo más destacable es que recomienda «... la norma de pronunciación conocida como castellano norteña. Los acentos propios de cada región son respetables, pero deben evitarse en intervenciones en cadena» (p. 81).

El Libro de estilo COPE no profundiza en aspectos ortológicos ni nombra las modalidades lingüísticas. Hay un breve apartado sobre pronunciación donde se advierte de que el esfuerzo por la pureza en la forma puede ir en detrimento de la naturalidad (COPE 2003: 92-95).

En Antena, libro de estilo del periodismo oral (Cadena SER 2017), aunque no abunda en las modalidades lingüísticas, refleja respeto por la diversidad en la pronunciación (es tan válido, se indica, decir /Miami/ como / Maiami/, según se diga desde una latitud u otra) y no impone ningún tipo de acento, sino que se opta por respetar el acento local o regional de cada zona. Considera que la vocalización clara y la articulación correcta de los sonidos son compatibles con la diversidad de acentos en el idioma español.

El manual de periodismo televisivo Libro de estilo de Canal Sur Televisión y Canal 2 Andalucía (Allas Llorente y Díaz Salgado 2004) es el único, hasta la fecha, que se refiere específicamente a la modalidad andaluza ${ }^{10}$. En la segunda parte, dedicada a la norma lingüística, se recoge un extenso capítulo en torno a la pronunciación en el que se dice que en Canal Sur Televisión tienen cabida todos los acentos del español siempre que sean inteligibles y que no se alejen en exceso del estilo formal:

... el periodista de Canal Sur TV puede optar por la pronunciación que prefiera, andaluza o castellana, pero recordando siempre que es preferible lo natural a lo artificioso, lo genuino a lo simulado. Tan inverosímil queda un informador andaluz forzando el acento castellano como un informa-

${ }^{10}$ Ha venido a sustituir al texto que apareció en 1991 bajo el título Libro de estilo. Canal Sur Televisión. 
dor castellano forzando el acento andaluz. Sin embargo, no debemos utilizar acentos excesivamente localistas ni pronunciaciones extremadamente relajadas o pedantes: estos usos no son propios del español estándar, concepto ideal de lengua que debemos perseguir en todo momento sea cual sea nuestro acento y sea cual sea nuestra procedencia (Allas Llorente y Díaz Salgado 2004: 218).

Bajo el epígrafe «Empleo de las hablas andaluzas» se precisa lo siguiente:

Todos los profesionales que se decidan a utilizar las hablas andaluzas en su labor ante el micrófono deben contribuir a que el andaluz no sea identificado únicamente con lo popular y lo coloquial, y mucho menos con lo vulgar. Aquellos rasgos del andaluz que utilicen en sus locuciones deben ser los que consideren de más alto nivel, aquellos que representen al mayor ámbito de la comunidad lingüística andaluza y, por supuesto, aquellos que carezcan de cualquier matiz que impida la comprensión. En otras palabras, deben emplear un andaluz culto y formal que abarque, amplíe y perfeccione el concepto de español estándar (pp. 218-219).

El yeísmo se considera correcto y propio del español estándar, como el seseo, aunque se añade que no resulta recomendable mezclar la pronunciación seseante con la distinguidora [cielo asul], pues denota inseguridad lingüística. Sobre la pronunciación de la letra $j$, describe que la realización fuerte es típica del español centronorteño, de varios países hispanoamericanos y del andaluz oriental, mientras que la aspirada es propia del andaluz occidental y de varios países hispanoamericanos. Debido a su escasa aceptación social se proscriben: la aspiración de la $h$, la confusión $r / l$ («A pesar de que esta es una pronunciación muy común en amplias zonas de Andalucía y América, su uso se restringe al registro coloquial y no se considera propio del español estándar», p. 223), la pronunciación fricativa relajada de la $c h$ («En exceso, esta relajación articulatoria suele resultar vulgar y no se considera parte del español estándar», p. 222), el ceceo («A pesar de que muchos andaluces utilizan el ceceo en su vida cotidiana, son también muchos los que abandonan esta práctica en registros más formales. Esto provoca que el ceceo no se considere propio del español estándar», p. 225), la combinación del ceceo con pronunciaciones seseantes o distinguidoras (pues generan inseguridad lingüística) y el heheo. Sobre la aspiración dice:

Antes de pausa o sonido consonántico, la letra $s$ puede pronunciarse de dos maneras: aspirada [h] o plena [s]. Cualquiera de estas pronunciaciones cumple con los requisitos de formalidad y estandarización propios del lenguaje informativo oral [...]. Sin embargo, cuando precede a una sílaba que comienza por vocal, en estilos formales es preferible la pronunciación plena (p. 225).

En cuanto a la abertura vocálica, el manual apunta: 
Es correcto utilizar la abertura vocálica para marcar la $s$ final de palabra. Esta práctica, muy extendida en todos los registros de Andalucía Oriental, no se da sin embargo, en otros lugares del mundo hispánico. Por esta razón, no es aconsejable utilizar una abertura vocálica muy amplia al menos que queramos conferir a nuestra pronunciación un marcado carácter local (p. 226).

A pesar de que el Libro de estilo de Canal Sur es el único que se refiere a la modalidad andaluza, lo que dice no es especialmente novedoso, pues coincide prácticamente con las «Pautas para locutores andaluces» propuestas con anterioridad por Vaz de Soto (1998); además, como ha señalado Méndez G. ${ }^{\text {a }}$ de Paredes, viene a ser «una descripción muy simplificada de formas de pronunciar que coexisten dentro de un espacio de variación y, a lo sumo, consejos para evitar ciertos vulgarismos, sean generales del español o específicos del andaluz» (Méndez G. ${ }^{a}$ de Paredes 2009: 280).

En cuanto al español de Canarias y el uso de esta modalidad lingüística en los medios de comunicación contamos hasta la fecha con los trabajos de Humberto Hernández, quien, en 2004, publica El mensaje en los medios. A propósito del estudio lingüistico de la prensa regional canaria, donde introduce un extenso capítulo sobre aspectos ortológicos que justifica del siguiente modo:

Estas consideraciones proporcionarán a los profesionales de la comunicación unos conocimientos básicos de fonética normativa que les servirán para compensar la ausencia de normas académicas a las que poder atenerse en las numerosas ocasiones de inseguridad del emisor de los mensajes y a evitar la desagradable sensación que produce en el receptor la falta de regularidad en la pronunciación y la constante vacilación, sobre todo en las áreas meridionales en las que se dan fenómenos, como el seseo o la aspiración de $-s$ implosiva, cuya legitimidad normativa suele ponerse, con frecuencia, en entredicho (Hernández 2004: 50).

Hernández defiende la necesidad de dos normas fonéticas, la modalidad castellana y la meridional y americana, como ya había defendido con anterioridad (Hernández 1998). En cuanto a la aspiración de la -s sigue lo ya propuesto por Ramón Trujillo (1981): no aspirar la $-s$ final de sílaba o palabra, no debilitar el timbre de las vocales, evitar el debilitamiento y sonorización de $p, t, c h, k$ (para que no se confundan con $b, d, y, g$ ), la confusión $r / l$, la pérdida de consonantes finales y la geminación o refuerzo de $b, d, y, g(\tan \text { peculiar del habla de Canarias })^{11}$.

En Norma lingüistica y español de Canarias. Manual de consulta para periodistas, Humberto Hernández (2009) introduce un primer capítulo sobre ortología y ortografía donde indica que el seseo, el yeísmo y la aspiración

11 Resultan de gran interés las catorce «Recomendaciones ortológicas generales», de aplicación para todo el ámbito hispánico (Hernández 2004: 82-84). 
de la $-s$ son rasgos de la modalidad dialectal canaria ${ }^{12}$. Cita el Diccionario panhispánico de dudas, donde se indica que «El seseo meridional español (andaluz y canario) y el hispanoamericano gozan de total aceptación en la norma culta», al igual que sucede con el yeísmo.

Para Humberto Hernández, los medios de comunicación hacen posible que entremos en contacto con cualquier lengua o dialecto del español europeo o americano, reforzando la unidad de las lenguas y haciéndola compatible con la diversidad dialectal: nacional, regional y local, pues promueven la convergencia lingüística limitando los usos divergentes. En este sentido, «sería conveniente que se difundieran las distintas variedades geográficas hispánicas de modo que se fueran extendiendo aquellas de mayor peso demográfico» (Hernández 2009: 35), contribuyendo así al conocimiento de otras modalidades. Por esta razón se muestra reacio a la tendencia de los medios a imponer un español neutro o internacional, que solo justifica en situaciones de comunicación muy concretas en que la expresividad no tenga demasiado interés, «como en ciertos textos informativos o en programas documentales de televisión, donde la imagen compensaría a la pobreza lingüística» (Hernández 2009: 35).

Ciertamente, la relación entre la diversidad lingüística y el español neutro es muy compleja, por lo que los medios de comunicación en la actualidad apuestan claramente por este último por una razón claramente comercial (Andión Herrero 2008). Está muy en boga en Hispanoamérica (para las locuciones publicitarias, el doblaje de películas, el material de formación...) y, sobre todo, en Estados Unidos (Gómez Font 2012: 90$)^{13}$.

\section{El DisCURSO DE LA PRENSA SOBRE LAS MODALIDADES ANDALUZAS Y CANARIAS} EN LOS MEDIOS DE COMUNICACIÓN

Como se demuestra en los trabajos publicados en Marimón Llorca y Santamaría Pérez $(2019)^{14}$, los textos periodísticos de divulgación lingüís-

${ }^{12}$ En cuanto a la aspiración de la $-s$ sigue lo ya propuesto por Ramón Trujillo (1981) y que recoge en Hernández (2004).

${ }^{13}$ En esta línea han surgido el Manual de estilo y referencia de la CNN en español (2002) -una revisión del realizado por Abel Dimant en 1999-, donde no se tratan aspectos ortológicos (tan solo dedica un párrafo a la fonética en nombres difíciles), y El Manual de estilo de la NAHJ (National Association of Hispanic Journalists) (Gómez Font 2003), publicado en Estados Unidos y realizado por periodistas de distintos medios y nacionalidades, que introduce cuatro páginas sobre la lengua oral con un apartado sobre errores comunes de dicción, entre los que nombra: la $-s$ final aspirada, la confusión $r / l$, la distinción $b / v$ y el ceceo, ya que el seseo está admitido.

${ }^{14}$ En esta monografía se reúne un conjunto de trabajos de los integrantes del Proyecto de excelencia METAPRES: El discurso metalingüistico en la prensa española (1940-hoy). Análisis multidimensional y caracterización, del que soy miembro. 
tica desempeñan un papel relevante en la transmisión de conocimiento, valores, actitudes y normas sobre la lengua en relación con sus contextos sociales e ideológicos concretos, de forma que no solo transmiten información sobre la lengua, sino que, a través de ellos, se construyen los conceptos y las identidades sociales e ideológicas tanto de la propia variedad como de sus hablantes.

De los 387 textos obtenidos en la Hemeroteca Virtual de las Lenguas de España (251 con la etiqueta «andaluz» y 136 con «canario»), 130 tratan sobre la relación de estas modalidades con los medios de comunicación. A continuación, pondremos de manifiesto las ideas que se vierten en ellos para poder establecer su relación con los estudios empíricos comentados en el estado de la cuestión.

\subsection{Sobre las modalidades andaluzas}

El $35 \%$ de los textos obtenidos en la Hemeroteca Virtual de las Lenguas de España con la etiqueta «andaluz» versa sobre el uso de esta modalidad en los medios de comunicación (en total 88 textos). Destacan las denuncias al destierro que sufre en los ámbitos formales, tanto en los medios locales como en los nacionales, a pesar de las indicaciones recogidas en el Estatuto de Autonomía y en el libro de estilo de Canal Sur (Allas Llorente y Díaz Salgado 2004):

(1) La mala influencia de tópicos arraigados durante siglos

Los medios de comunicación y la cultura han fomentado una imagen estereotipada asociada a la falta de formación y seriedad.

[...] Sin ir más lejos, en Canal Sur, buena parte de los periodistas siguen forzando la pronunciación en favor del uso de la modalidad castellana. A pesar de que tanto el Libro de Estilo de la cadena autonómica como el Estatuto de Autonomía recogen la necesidad de promover el reconocimiento y uso del andaluz «en sus diferentes hablas» (<diariosur.es>/Málaga, 18/01/2009).

En general, los discursos de la prensa sobre la alternancia vernáculo/ estándar en los medios de comunicación están basados en los conceptos de lealtad/deslealtad o estimación/no estimación hacia la propia modalidad, con lo que se llega a la conclusión de que, como la modalidad andaluza no es digna ni prestigiosa, el hablante, por complejo de inferioridad, la abandona en contextos formales. De hecho, un aspecto interesante reiterado en la prensa es que esto no sucede en el caso de otras variedades lingüísticas. La siguiente columna de opinión, firmada por Manuel Molina, escritor y profesor de Lengua y Literatura, subraya el «menosprecio o falta de valoración» por parte de los andaluces hacia su propia modalidad, razón por 
la que estos ocultan sus rasgos (alusión implícita el complejo de inferioridad); critica, además, que el acento andaluz solo aparezca en contexto humorístico. Según el autor, este hecho no les ocurre ni al canario (sin embargo, como comprobaremos posteriormente, desde la prensa canaria la percepción es totalmente opuesta) ni al argentino:

(2) El andaluz, los medios y la que faltaba

... Lo que sí llama poderosamente la atención es el menosprecio o falta de valoración que desde los propios andaluces tienen sus variantes lingüísticas. Pongamos un claro ejemplo y todo el mundo podrá entenderlo. Una presentadora andaluza ocultará o le harán ocultar su acento en los medios de comunicación, pero si es canaria o suramericana (variantes a su vez del andaluz) nunca lo esconderán. Baste recordar a la periodista Cristina García Ramos (canaria) con su meloso seseo ('Corasón, corasón') o la cantidad de anuncios con voces argentinas que pueblan las pantallas; incluso el mismo entrenador mexicano del Atlético de Madrid, Aguirre: «'Quisásss' no 'asertamosss' con la puerta».

¿Por qué ocultamos nuestros rasgos en cuanto tenemos contacto con la variante castellana o con una pantalla? La razón en primer lugar quizá radique en que los propios medios, en especial los de producción andaluza, lo propician eliminando presentadores con rasgos lingüísticos andaluces. En la televisión pública tan sólo conozco unas variantes claras y son programas de humor: 'Colga2 con Manu', Paz Padilla o los monstruos de Juan Imedio. Para la chufla existe hueco, para la seriedad, no. [...] (<ideal.es>/Jaén, 18/01/2009).

En la misma línea incide el siguiente texto, donde el periodista Alfonso Vázquez contrasta la actitud del hablante andaluz con la del catalán para demostrar el complejo de inferioridad que padece el primero:

(3) El doble complejo de inferioridad del andaluz

... En segundo lugar, el complejo de inferioridad del hablante andaluz, mayoritario entre los locutores de radio y televisión de Andalucía (Málaga, por desgracia, incluida) pero también entre muchos políticos de nuestra comunidad, que piensan de forma totalmente equivocada que el español que se habla en Andalucía es un error de dicción que debe corregir el logopeda.

[...] Posiblemente seamos la única comunidad autónoma de España con estos dos complejos de inferioridad tan en boga -que uno sepa, ningún locutor catalán ha ido al logopeda para dejar de pronunciar con tanta fuerza la ele, y hace muy bien- (<laopiniondemalaga.es>, 27/02/2016).

La siguiente columna, de la lingüista Elena Álvarez Mellado, argumenta que el locutor andaluz oculta sus rasgos en la televisión nacional («maquilla», «dicción impostada», «operación de cosmética fonética») porque siente su modalidad como una "variedad de segunda», «no seria» y «no válida» 
para ámbitos formales; pero no por una cuestión lingüística, sino por una cuestión de prestigio social basada en hechos históricos. El subtitular incide en los tópicos equivocados que se acaban difundiendo cuando parten de gente inexperta («los cuñados de la lengua») ${ }^{15}$. Se insiste en que la variedad andaluza ha salido particularmente malparada y se culpa a los medios de comunicación de la representación recurrente y estereotipada que sufren los andaluces tanto por parte de la ficción audiovisual como de los presentadores. Termina con un alegato a favor de que los medios usen la modalidad andaluza, única forma de contribuir a su normalización:

(4) No hablarás con acento andaluz en el telediario de las 9

Aunque ningún lingüista serio defendería la existencia de variedades de español buenas y malas, los cuñados de la lengua siguen proclamando con entusiasmo que el mejor español es el de Valladolid y que los andaluces hablan fatal.

[...] Y es que el acento andaluz en los medios de comunicación es aceptable siempre que lo usen folklóricas, toreros y cómicos. Los Morancos pueden tener acento andaluz, pero Velázquez y Picasso (andaluces ambos) hablan un perfecto castellano mesetario en la serie El Ministerio del Tiempo. El personaje de Merche en Cuéntame tuvo acento andaluz en los primeros episodios de la serie, pero finalmente se descartó.

[...] En el gremio de presentadores la cosa tampoco anda mucho mejor en lo que a variedad lingüística se refiere: es sorprendente lo que cuesta imaginar a locutores de telediario dando las noticias en la tele pública nacional hablando con un acento que no sea el estándar precocinado. Resulta refrescante escuchar a la presentadora de Masterchef Eva González hablando antes de que se le llenara la pronunciación de eses forzadas o descubrir al que fue durante años el hombre del tiempo en TVE1, José Antonio Maldonado, sesear en una entrevista informal en CanalSur. Bajo todos esos frentes de altas y bajas presiones, se escondía un seseante disfrazado de mesetario.

¿Por qué Eva González tiene que maquillar su acento natural bajo capas de dicción impostada cuando habla en TVE-1? En último término, la idea que subyace a la operación de cosmética fonética a la que se somete a quienes hablan con acento andaluz en la televisión nacional es que hay formas de hablar que son aceptables en la esfera pública y variedades de segunda que, aunque pueden tener gracejo, deben permanecer en el ámbito de lo doméstico porque no son serias o válidas. Pero el origen de este doble rasero es una cuestión de poder, no de lengua.

[...] La televisión tiene un enorme poder en lo que a representación y normalización cultural se refiere. De la misma manera que esperamos

15 «El término cuñadismo, que hasta ahora hacía referencia al nepotismo o favoritismo hacia los cuñados, ha ampliado su significado y se emplea sobre todo para referirse a la tendencia a opinar sobre cualquier asunto, queriendo aparentar ser más listo que los demás». (<https://www.fundeu.es/recomendacion/cunadismo-nuevo-significado/>). 
que la televisión pública recoja los distintos intereses y sensibilidades de la población, sería muy deseable ver reflejado y celebrado todo el abanico de diversidad lingüística de la sociedad en que vivimos y abandonar de una vez el monocultivo del castellano central que copa nuestras pantallas. Y hoy, día de Andalucía, es un buen día para reclamarlo (<eldiario.es>, 27/02/2017).

Como puede apreciarse, en la prensa se reivindica la necesidad de hablar andaluz en todas las situaciones, ya que el que en los registros de distancia comunicativa y formalidad los hablantes cultos suelan seguir el modelo estándar se interpreta como si la andaluza no se considerara una modalidad digna o suficientemente prestigiosa. Para conseguir que lo sea, se repite la hipótesis de que si los profesionales hablaran andaluz en los medios, servirían de modelo ejemplarizante al que podrían acogerse los andaluces en situaciones formales (Méndez G. ${ }^{a}$ de Paredes 2013: 307). Los discursos que tienen que ver con la promoción de una norma andaluza de carácter culto que satisfaga las expectativas comunicativas en situaciones formales y sirva de referencia y modelo de actuación lingüística vienen reiterándose desde la Transición y, como señala Méndez G. ${ }^{a}$ de Paredes (2019: 205): «el locus funcional de esta norma son los medios de comunicación, pues se presupone que son agentes irradiadores de norma».

En la prensa autonómica se reiteran los textos que culpan a los medios de comunicación (cine, televisión, dibujos animados, etc.) de fomentar el estereotipo negativo del hablante andaluz, pues se le asocia constantemente a personajes graciosos e incultos que aparecen relegados a los ámbitos humorísticos y de entretenimiento. De hecho, el Partido Andalucista ${ }^{16}$ impulsó una proposición no de ley de la Junta de Andalucía (aprobada en 2005) para erradicar dicha realidad:

(5) No a la ridiculización del andaluz en la tele

¿Por qué todos los personajes andaluces de las series hablan mal y son exagerados? La Juani de Médico de familia, la cocinera de Ana y los siete, en Siete vidas, Aquí no hay quien viva...

El Parlamento andaluz respaldó ayer una iniciativa del PA contra la ridiculización de los andaluces en televisión. Insta a la Junta a que lleve a cabo campañas que refuercen la imagen en positivo de los andaluces. «Estamos siendo estereotipados y exagerados», afirman los andalucistas. La proposición no de ley aprobada ayer rechaza el rol negativo que los guionistas le asignan a los andaluces. No se oponen al acento, pero sí a la forma de expresarse que le otorgan a estos personajes, incidiendo en un bajo nivel cultural para conseguir un gag humorístico basado en las faltas de los andaluces (<20minutos.es>/Andalucía, 13/05/2005).

${ }^{16}$ El Partido Andalucista ha reivindicado constantemente la presencia de la modalidad andaluza en los medios de comunicación (véase Méndez G. ${ }^{a}$ de Paredes 2009: 226-227). 
Esta denuncia del estereotipo del hablante andaluz es recurrente, de forma que aparece cada cierto tiempo en la prensa autonómica, y, ocasionalmente en la nacional (como podemos apreciar en 8). Se culpa a los medios de asociar el acento andaluz a un nivel cultural bajo, a cómicos y a personas vagas:

(6) De «la Juani» de «Médico de familia» a la entrevista de Melody: el polémico tópico andaluz

... En las series de televisión ha sido fácil ver cómo los personajes con un nivel cultural más bajo eran, en muchos casos, andaluces. Uno de los más conocidos es el papel de «la Juani», la criada andaluza que trabajaba en la casa del doctor Nacho Martín en la exitosa serie «Médico de familia».

[...] En cuanto a casos más recientes, tampoco sentó demasiado bien en las redes sociales el comentario que la actriz y cómica Eva Hache realizó durante la presentación de la gala de los Goya 2013 cuando se dirigió al director de la película «Grupo 7», Alberto Rodríguez, para decirle, en tono de broma, que se habría agradecido poner subtítulos a los yonquis sevillanos que salían en el largometraje (<abc.es>/Sevilla, 01/09/2014).

(7) ... por alguna razón, el caso andaluz sobrepasa ese límite y la imagen de vagos y humoristas del sur de España suele predominar sobre el resto de forma bastante notoria, muchas veces debido a la influencia de la televisión -Emilio Delgado, Fernando Tejero, en Aqui no hay quien viva, o más recientemente, Tere, Sara Vega, en Anclados- pero sin olvidar entonar un 'mea culpa' con espacios como los de Canal Sur, donde se fomenta especialmente el estereotipo andaluz (<granadahoy.com>, 03/11/2015).

(8) Por qué el personaje 'gracioso' de los dibujos animados siempre tiene que tener acento andaluz

En la Jungla. Desde Gazpacho de 'Los Fruitis' hasta el Gato Jinks de 'Pixie y Dixie' o los propios Simpsons, los dibujos suelen dar las particularidades fonéticas del dialecto andaluz a los personajes más cómicos o de clases sociales más bajas (<elespanol.com>, 28/01/2017).

Sin embargo, a pesar de la repetición de argumentos, en los últimos años se recogen tanto en la prensa local como nacional, testimonios de actores y periodistas que sienten que se está produciendo una revalorización de la modalidad andaluza y un cambio positivo hacia su hablante, lo que está haciendo variar la imagen que se tiene de los andaluces en el resto de España. Así se manifiesta el actor gaditano Álex O’Dogherty (9), la periodista Marta Jiménez (10) y la actriz Carmen Frigolet (11):

(9) La cuestión del acento neutro [...]

El andaluz se despoja paulatinamente de los estigmas impuestos en el habla en el sector audiovisual [subtitular]

[...] Durante décadas, los actores andaluces han necesitado aprender a pronunciar con el llamado acento neutro para poder ser contratados 
en el sector audiovisual. «Esto era así. Si no sabías ocultar tu acento andaluz tus papeles se limitaban a hacer de camarero o Guardia Civil, quedabas relegado a papeluchos, nunca protagonistas. Pero a partir de Padre Coraje (2002) esta concepción ha ido cambiado. Ahora puedes aparecer en cualquier serie perfectamente siendo andaluz sin que conlleve nada más», considera el actor de San Fernando Álex O’Dogherty, que tras más de 20 años de carrera nacional e internacional ha vivido el proceso que estigmatiza la interpretación de los andaluces por sus acentos (<elpais.com>, 22/02/2016).

(10) «... Hoy muchos actores y actrices hablan con acento andaluz hagan la película que hagan. Antes les obligaban a cambiarlo, como nos ocurría también a los locutores de radio. Afortunadamente, ya no ocurre» (<elespanol.com>, 28/01/2017).

(11) «Los actores hemos superado el complejo de hablar en andaluz».

«En 'Allí abajo' ya vamos por la quinta temporada. Por fin vamos superando el complejo de ser andaluces y hablar en andaluz. A no ser que te indiquen lo contrario, ¿por qué tienes que renunciar a tu acento? Hace poco tuve que interpretar a un personaje madrileño. En ese caso sí tenía sentido. Si no, hablemos en andaluz», dice Carmen en referencia al habla andaluz de los actores.

«Creo que el cambio vino a raíz de la película 'Solas'. Antes llegabas a un casting y te decían: “¿Lo puedes castellanizar?”. Ahora ya no. Tú les preguntas: “¿Qué estás buscando exactamente?”. Porque entender, se nos entiende perfectamente...», explica (<lavozdigital.es>/Cádiz, 14/05/2019).

Algunos testimonios presentan como una opción personal, y no una imposición del medio, la elección de la modalidad andaluza o de la septentrional. Por tanto, el suavizar los rasgos andaluces en determinados contextos no tiene por qué deberse al reiterado complejo de inferioridad, sino que puede obedecer a otras razones, como al hecho de que los hablantes sientan como suyos los rasgos del español general, a los que recurren en situaciones comunicativas que tienen que ver con una actitud más abarcadora de tipo panhispánico (Méndez G. a de Paredes 2003: 171). Esta parece ser la razón que lleva a la periodista Flora González a cambiar su acento:

(12) Flora González, periodista jiennense y presentadora de la información meteorológica en la cadena de televisión Cuatro.

[...] «Yo soy un mero transmisor, tengo una información, en este caso meteorológica, que tengo que codificar para que llegue de la forma más clara al espectador. Cuando intervengo en programas donde además de periodista soy un personaje -en referencia a sus apariciones en el espacio de la también presentadora andaluza Toñi Moreno-ahí sí lo hago con mi acento» (<abc.es>/Sevilla, 09/07/2018). 
Un dato curioso que se apunta desde la prensa (tanto autonómica como nacional) y que también puede contribuir a la revalorización de la modalidad andaluza es el hecho de que los políticos la empleen como estrategia electoral para empatizar con los votantes:

(13) Con acento andaluz

Los candidatos han utilizado el seseo y otros rasgos del habla andaluza; quieren mostrar que no menosprecian a los votantes.

[...] Posiblemente, los candidatos han hallado en el acento, por vía empática y emocional, una forma de acercamiento muy persuasiva; con él tratan de defender que están cercanos a la gente, que no menosprecian a sus votantes, que defienden sus intereses y que respetan una de las primeras marcas de identidad, la forma de hablar. Pero aunque sea por esa pensada estrategia, solidaria de gestos campechanos clásicos como el beso al bebé o la mano extendida en el mercado, el hecho es que este auge de la forma lingüística andaluza en el discurso político rema en una dirección positiva: la aparición de la pronunciación andaluza en la tribuna pública y no solo en los personajes de estratos bajos de la ficción audiovisual (<elpais.com>, 20/11/2018).

(14) A Inés Arrimadas se le pega el acento gaditano en campaña (<elpais.com>, 29/11/2018).

El profesor e investigador experto en las modalidades andaluzas, Antonio Narbona Jiménez, también se muestra positivo ante la normalización del acento andaluz, aunque reconoce, como advertimos en el siguiente titular, que va a la cola del resto de variedades meridionales:

(15) Antonio Narbona: «El acento andaluz será tan normal como el canario o sudamericano»

El catedrático Antonio Narbona cree que se está perdiendo el estigma que le asocia a viejos tópicos y será habitual escucharlo en medios de comunicación (<abc.es>/Sevilla, 09/07/2018).

Narbona incide en el importante papel de los medios de comunicación, no solo por presentar con normalidad la modalidad culta del andaluz, sino por ser un canal esencial para divulgar un conocimiento lingüístico experto que contrarreste el peso de los tópicos negativos que han recaído históricamente sobre ella:

(16) A vueltas con la defensa del andaluz

[...] Los obstáculos con que tropieza la labor de difundir y divulgar el conocimiento de las hablas andaluzas pueden superarse, y en ello estamos. Los medios de comunicación audiovisuales y escritos pueden y deben tener un papel clarificador decisivo (<diariodesevilla.es>, 26/03/2017). 
Por último, destaca un grupo de textos publicados en 2017 que ha reactivado los discursos victimistas que abundaron en la Transición amparados por determinadas ideologías políticas e influidos por el resurgir nacionalista, coincidente con el proceso independentista de Cataluña. Se trata de discursos de autoconstitución identitaria, ideológicamente sesgados, que presentan una polarización entre «nosotros» (los andaluces/las víctimas) y «ellos» (los no andaluces), y que inciden tanto en los tópicos positivos (vanguardismo, creatividad, economía, musicalidad...) como en los negativos (el desprestigio histórico, el complejo de inferioridad...). Veamos como ejemplo el siguiente texto de Javier Martín González, profesor de Lingüística Inglesa en la Universidad de Sevilla, en el que arremete contra los que, a su vez, se han manifestado en contra de la propuesta de creación de una Academia Andaluza de la Lengua (marzo de 2017) y de la traducción al andaluz de El Principito (mayo de 2017), dos hechos de enorme repercusión mediática (Guerrero Salazar 2020: 119-123). El profesor defiende estas iniciativas, pues, según él, tratan de combatir «la estigmatización y la nefasta discriminación lingüística que los andaluces seguimos padeciendo» por parte de «la cultura colonizadora castellanizante del centralismo nacionalista español» (claro eje nosotros/ellos). El texto apela al orgullo de expresarse en andaluz y culpa de nuevo a los medios de comunicación (también al sistema educativo), de contribuir a la estigmatización de la modalidad, al presentar una imagen ridícula y distorsionada de sus hablantes:

(17) La discriminación de la realidad lingüística andaluza

Y es que la estigmatización lingüística siempre ha sido un arma muy poderosa y efectiva para las culturas colonizadoras. No es ninguna sorpresa, por tanto, que los andaluces hayamos sufrido y sigamos sufriendo este tipo de discriminación a manos del empuje colonizador castellanizante del centralismo nacionalista español. Por no mantenernos en un pasado demasiado remoto, baste con señalar la imagen que se promovió del andaluz durante la última dictadura, con su ideal de unidad castellana y su intento de peyorizar nuestra tierra y nuestra cultura autóctonas, folclorizando nuestra lengua y presentando una imagen ridícula y distorsionada de sus hablantes. Se nos estigmatizó continuamente desde la escuela y los medios de comunicación. Por desgracia, la base de ese mensaje y la actitud discriminatoria que este representa contra nuestra realidad lingüística sigue existiendo tanto fuera como dentro de Andalucía (<lavozdelsur.es $>/$ Jerez, 04/06/2017).

\subsection{Sobre las modalidades canarias}

De los 136 textos relacionados con la modalidad canaria extraídos de la Hemeroteca Virtual de las Lenguas de España, el $31 \%$ hace alusión a los 
medios de comunicación (en total 42 textos). Llama la atención que en el caso del canario no hay ningún ejemplo procedente de la prensa nacional.

Por una parte, encontramos noticias que manifiestan quejas sobre la ocultación de la modalidad canaria en los medios de comunicación, lo cual se alega como causa del desprestigio histórico que viene sufriendo:

(18) Juan M. Pérez Vigaray [...] ha lamentado que todo lo que se escucha en televisión, incluso en los informativos locales o regionales, usa el español de forma «monótona y sin acentos». [...] En su opinión, este proceso de universalización lingüística es «realmente peligroso» y cree que responde a una «motivación económica». Esto, explicó, lo ha detectado uno de sus alumnos, que ha decidido realizar un trabajo de fin de grado sobre un estudio respecto a las cuñas que se emiten en una importante emisora en las islas, en donde todos los anuncios usan un español que no se habla en Canarias, incluso aquellos institucionales de Gobierno y Cabildos (<europapress.es>/Islas Canarias, 04/12/2014).

Se hace presente también el tópico del complejo de inferioridad que sienten los hablantes. Así lo manifiesta el experto José Antonio Samper, catedrático de Lengua Española de la Universidad de Las Palmas de Gran Canaria y en ese momento presidente de la Academia Canaria de la Lengua:

(19) También apunta algo importante para la preservación de la modalidad canaria del español: «Hay que quitarse complejos». Y eso consiste en «no renunciar a la forma de hablar canaria para adoptar otra que se cree más prestigiosa, cuando no lo es» (<canarias7.es>, 01/06/2016).

Se incide en que el uso de la modalidad canaria en los medios de comunicación locales está relacionado con el humor, sin embargo, no hay ningún ejemplo sobre que los medios presenten un estereotipo negativo del hablante canario (lo que es un tópico recurrente en el caso del andaluz):

(20) Un experto asegura que el humor isleño está basado en el lenguaje El profesor titular de Lengua Española de la Universidad de Las Palmas de Gran Canaria (ULPGC) Juan M. Pérez Vigaray ha asegurado que el humor que se hace en las islas está basado en cómo se emplea el lenguaje... (<europapress.es>/Islas Canarias, 04/12/2014).

Se reitera una y otra vez la responsabilidad de los medios de comunicación en cuanto a la normalización de la modalidad. El catedrático y director actualmente de la Academia Canaria de la Lengua, Humberto Hernández, es el experto que opina en los tres ejemplos siguientes:

(21) Hablar canario en los medios de comunicación

Humberto Hernández, Profesor de Periodismo de la ULL, pide normalizar el canario culto en la comunicación que se realiza en Canarias. Todo ello, 
en busca de una comunicación más natural y auténtica (<tamaimos.com>) Islas Canarias, 03/02/2016).

(22) Canarismos en su justa medida

Los medios de comunicación, tanto audiovisuales como escritos, tienen una enorme responsabilidad para con la lengua y, en el caso de Canarias, aún más si cabe. Como hablen los periodistas canarios en la radio y en la televisión y también como escriban en prensa contribuirá, o no, a la normalización y homogeneización de la unidad lingüística de las Islas.

El buen uso de la lengua en general y, en particular, de la modalidad lingüística canaria es una de las preocupaciones que reiteradamente muestran los académicos de la Academia Canaria de La Lengua (ACL) que, además, no dudan en destacar el «importante» papel que desempeñan los medios de comunicación en la promoción y normalización de la modalidad lingüística canaria.

[...] «se habla un buen español de Canarias en radios y televisiones», pero que tiene un problema en forma de «enemigo», que no es otro que «la influencia permanente y constante del español castellano» en los medios de comunicación, que hace que muchos canarios cedan ante su influencia, atenuando los rasgos propios (<canarias7.es>, 03/07/2017).

(23) La escuela quiere quitar complejos y poner en valor el habla canaria [...] Humberto Hernández, considera fundamental «quitar complejos», pero advierte de que «no se trata de enseñar de forma separada el español de Canarias, ni de manera artificial, porque los chicos ya hablan canario», sino de "contrarrestar la enorme influencia del español de los medios de comunicación y las redes sociales». Y recuerda que «el $90 \%$ de las emisiones de radio y televisión vienen en la modalidad castellana» (<canarias7.es>, 31/05/2018).

Por último, también hay experiencias en prensa que muestran un cambio hacia la valoración de la propia modalidad, por lo que determinados periodistas ya no ocultan los rasgos de su variedad para intervenir en medios nacionales:

(24) No quiero quedarme en ejemplos personales, porque sin ir más lejos, todos los días hablan en la Cadena SER, para todo el Estado, dos canarios. Se trata de Eva Vega, que normalmente ofrece la información económica y de Nicolás Castellano, que diserta sobre el fenómeno de la inmigración y suele ser enviado especial a zonas de interés informativo. Eva Vega habla de los movimientos de la bolsa con acento canario, totalmente reconocible y muy natural, sin forzar ni una cosa ni otra. Nicolás Castellano pide paso desde Lampedusa, un campo de refugiados en Siria o desde Ceuta, con dicción canaria y natural. ¿Cuántas veces hemos escuchado que para trabajar en los medios estatales es necesario cambiar el acento? ¿Cuántos de los que trabajan aquí, solo por el hipotético caso de que los llamen de allá o por mero complejo, cambian su forma de hablar? ¿Cuántos vienen 
de universidades estatales hablando castellano porque «se les pegó el acento»? En pleno siglo XXI, es hora de que acabemos con los tópicos acomplejados y surquemos con identidad y naturalidad una nueva era en la comunicación en Canarias. Eva Vega y Nicolás Castellano, entre otros, nos sirven de ejemplo (<tamaimos.com>/Islas Canarias, 03/03/2016).

\section{Resultados}

A través de la muestra en prensa analizada (130 textos), hemos podido constatar que los textos que tratan sobre medios de comunicación y andaluz son más numerosos (88) que los que tratan sobre medios de comunicación y canario (42) y que, mientras los primeros proceden tanto de prensa nacional como local, en el caso del canario, solo son de ámbito local. En cuanto a los temas comunes en torno al uso de las modalidades andaluzas y canarias en los medios de comunicación destacan los siguientes:

1) Textos que inciden en que sobre ambas modalidades pesa una estigmatización de español no correcto e ininteligible que todavía está en la mente de los hablantes y que se ve favorecida, por un lado, por el hecho de aparecer en formatos humorísticos y espacios de entretenimiento, mientras que apenas tienen cabida en las informaciones que requieren cierta formalidad, lo que las asocia con el humor (sobre todo el andaluz, más ligado al estereotipo). Además, el desprestigio social de estas modalidades conlleva en los periodistas cierta deslealtad lingüística, es decir, la ocultación de sus rasgos propios en situaciones formales.

2) Textos que denuncian que el modelo de referencia que aportan los medios audiovisuales y radiofónicos sigue siendo mayoritariamente el estandarizado septentrional y que apenas tienen cabida los rasgos típicos ni andaluces ni canarios, sino los propios de la variedad estándar del español centropeninsular o norteño.

3) Textos que se hacen eco de los tópicos que históricamente han versado sobre estas modalidades y que aluden a los complejos de inferioridad de sus hablantes para justificar que estos disimulen su acento ante los medios de comunicación.

4) Textos que tratan sobre el papel determinante de los medios de comunicación en cuanto al prestigio y desprestigio de las modalidades lingüísticas pues, dada su labor difusora y su consideración como autoridad lingüística para los hablantes, podrían constituir una plataforma idónea desde la que proyectar un modelo de pronunciación meridional basado en todos aquellos rasgos de prestigio presentes en estas modalidades, para que, finalmente, se tengan 
por una variante válida frente al modelo norteño. Por otra parte, también pueden ejercer de canal a través del cual divulgar el conocimiento experto sobre las modalidades, única manera de competir con los tópicos negativos.

5) Textos que constatan un cambio de actitud hacia estas modalidades, cada vez más presentes en los medios de comunicación nacionales por medio de locutores y artistas que no se sienten obligados a disimular su acento, o de políticos que lo utilizan para ganar adeptos en las campañas electorales.

\section{Conclusiones}

El análisis de los once libros de estilo (1985-2017) que nos marcamos como primer objetivo de este trabajo ha puesto de manifiesto que, aunque cabría esperar que aquellos que han surgido al amparo de los medios de comunicación audiovisuales y, sobre todo los radiofónicos, trataran las cuestiones ortológicas con detenimiento; sin embargo, o no dicen nada, o dedican muy poco espacio a este tema, o son poco rigurosos; estos manuales, en general, se limitan a proscribir algunos vulgarismos en la pronunciación, el cambio de acentuación o determinadas curvas de entonación. No obstante, hemos constatado que lo poco que incluían sobre ortología ha ido cambiando, pues los libros de estilo actuales ya no marcan las pautas del español septentrional ni se proscribe el yeísmo o el seseo (como se hacía en los noventa), sino que contemplan el respeto por la diversidad en la pronunciación. En cuanto a los manuales que abordan concretamente las modalidades estudiadas, solo existen actualmente el de Canal Sur (Allas Llorente y Díaz Salgado 2004) para el andaluz y los trabajos de Hernández (2004 y 2009) para el canario.

En cuanto al segundo objetivo, la percepción que se difunde desde la prensa sobre el uso o no de estas modalidades en los medios de comunicación, los textos analizados constatan cómo los hablantes creen que las modalidades andaluzas y canarias van ganando prestigio. Estas apreciaciones coinciden con los resultados de los trabajos sociolingüísticos más recientes, los cuales revelan un cambio de actitud en los hablantes sobre la valoración hacia su propia modalidad. No obstante, siguen corroborando que muchos de ellos, sobre todo profesionales de los medios, tienden a renunciar a los rasgos de su modalidad y a adoptar los del modelo norteño. Aunque la causa más reiterada es la deslealtad debida al complejo de inferioridad, el suavizar los rasgos en determinados contextos puede obedecer a otras razones, como a la imposición del propio medio o al hecho de que los hablantes sientan como suyos los rasgos del español general, a los 
que recurren en situaciones comunicativas que tienen que ver con una actitud más abarcadora de tipo panhispánico.

A la luz de los resultados cabría preguntarse si, entre los posibles factores que están contribuyendo al cambio de actitud, pueden estar, entre otros, los libros de estilo (que ya no imponen abiertamente los rasgos del español septentrional) y la labor divulgadora de conocimientos lingüísticos llevada a cabo en los medios de comunicación por expertos lingüistas. 


\section{BIBLIOGRAFÍA}

\section{BIBLIOGRAFÍA CRÍTICA:}

ACAdemia Española y Asociación de ACAdemias de la Lengua Española (2010): La ortografia de la lengua española, Madrid: Espasa.

- (2018): Libro de estilo de la lengua española según la norma hispánica, Madrid: Espasa.

Andión Herrero, M. a Antonieta (2008): «La diversidad lingüística del español: la compleja relación entre estándar, norma y variedad». En Antonio Moreno Sandoval (coord.), El valor de la diversidad (meta)lingüistica. Actas del VIII congreso de Lingüistica General, Madrid: Universidad Autónoma de Madrid, 294-307.

Armas Marrón, Ana Cristina (2002): «El habla canaria en la prensa local de Tenerife», Revista Latina de Comunicación Social 50. <https://www.ull.es/publica ciones/latina/2002/latina50mayo/5010armas.htm>.

Carbonero Cano, Pedro (2011): «Sobre la normalización lingüística en Andalucía: antecedentes y perspectivas». En Yolanda Congosto Martín y Elena Méndez G. ${ }^{a}$ de Paredes (eds.), Variación lingüistica y contacto en el mundo hispánico, Madrid/Frankfurt: Iberoamericana/Veruvert, 73-87.

Carrascosa Pulido, José Luis (2002): «El habla en los informativos andaluces de radio y televisión y en el cine». En Jerónimo de las Heras et al., (eds.), Modalidad lingüistica andaluza. Medios de comunicación y aula, Huelva: J. Carrasco, $39-45$.

CARvajal, Nani (2002): «El habla andaluza en los medios de comunicación», en De las Heras et al. 2002, 47-59.

Cestero Mancera, Ana M. ${ }^{\mathrm{a}}$ y Florentino Paredes García (2015): «Creencias y actitudes hacia las variedades normativas del español actual: primeros resultados del Proyecto PRECAVES-XXI», Spanish in Context, 255-279.

- y - (2018): «Creencias y actitudes hacia las variedades cultas del español actual: el Proyecto PRECAVES XXI», Boletín de Filología 53/2, 11-43.

ĎAĎOvÁ, Zuzana (2017): «Mercado lingüístico y variación sociofonética en los informativos de la Televisión Canaria», Verbeia 3/2, 9-29.

DE LAS Heras, Jerónimo et al. (eds.) (2002): Modalidad lingüistica andaluza. Medios de comunicación y aula, Huelva: J. Carrasco.

Díaz SAlgado, Luis Carlos (2002): «Creencias y actitudes sobre usos fónicos "innovadores" del andaluz en los periodistas sevillanos de Canal Sur Televisión», Tonos Digital 3. <http://www.um.es/tonosdigital/znum3/estudios/fonosim bolismo.htm $>$.

Fontanillo, Enrique y M. ${ }^{a}$ Isabel Riesco (1994): Teleperversión de la lengua, Barcelona: Anthropos.

GARRIDO MEDINA, Joaquín (1994): Idioma e información. La lengua española de la comunicación, Madrid: Síntesis. 
Gómez FonT, Alberto (2012): «Español neutro, global, general, estándar o internacional». En Escribir en internet. Guía para los nuevos medios y las redes sociales, Barcelona: Galaxia Gutenberg.

Gómez Torrego, Leonardo (2002): Manual de español correcto, 2 vols., Madrid: Arco/Libros.

Guerrero Salazar, Susana (2020): «Análisis comparativo de las actitudes lingüísticas sobre las modalidades andaluzas y canarias en la prensa española», Moderna Språk 114/1, 108-138. <http://ojs.ub.gu.se/ojs/index.php/moderna sprak/article/view/4671>.

Hernández Cabrera, Clara Eugenia y Marta SAmper Hernández (2018): «Creencias y actitudes de los jóvenes universitarios canarios hacia las variedades cultas del español», Boletín de Filología 53/2, 179-208.

HERNÁNDEZ-CAMPOY, Juan Manuel (2004): «El fenómeno de las actitudes y su medición en sociolingüística», Tonos digital 8, 29-56. <https://www.um.es/tonos digital/znum8/portada/monotonos/04-JMCAMPOYa.pdf $>$.

HERNÁNDEZ HERNÁNDEZ, Humberto (1998): «En defensa de la ortología (hacia una fonética normativa del español actual)», Español Actual 70, 37-55.

JIMÉNEZ FERNÁNDEZ, Rafael (2002): «El andaluz en los medios de comunicación: la caricatura lingüística del sur». En De las Heras et al. 2002, 187-194.

León-Castro Gómez, Marta (2016): «La presencia del andaluz en los medios de comunicación», Actas del I Congreso Internacional Comunicación y Pensamiento: comunicracia y desarrollo social, Sevilla: Universidad de Sevilla, 1583-1600.

Manjón-Cabeza Cruz, Antonio (2018): «Creencias y actitudes de los jóvenes universitarios granadinos hacia las variedades cultas del español», Boletín de Filología 53/2, 145-177.

Marimón Llorca, Carmen e Isabel SAntamaría Pérez (eds.) (2019): Ideologías sobre la lengua y medios de comunicación escritos. El caso del español, Berlín: Peter Lang.

Medina Guerra, Antonia María (2002): «Ortología». En M. ${ }^{a}$ Victoria Romero Gualda (coord.), Lengua española y comunicación, Barcelona: Ariel, 179-211.

- (2005): «Algunas consideraciones en torno a los rasgos dialectales en los manuales de estilo». En Susana Guerrero Salazar y Antonia M. ${ }^{a}$ Medina Guerra (coords.), Lengua española y medios de comunicación: Norma y uso, Málaga: VG Ediciones, 96-107.

- (2008): «Oralidad y escritura en el lenguaje radiofónico». En Antonio Arroyo Almaraz (coord.), La lengua española en los medios de comunicación y en las nuevas tecnologías, Madrid: Laberinto, 341-379.

MÉNDEZ GarCía de PAREDEs, Elena (2003): «El andaluz en la prensa (actitudes lingüísticas: 1980-1981)». En Carmen L. Reina Reina (coord.) y Antonio Narbona Jiménez (dir.), II Jornadas sobre el habla andaluza: el español hablado en Andalucía, Estepa: Ayuntamiento, 139-174.

- (2009): «La proyección social de la identidad lingüística de Andalucía. Medios de comunicación, enseñanza y política lingüística». En Antonio Narbona Jiménez (coord.), La identidad lingüistica de Andalucía, Sevilla: Centro de Estudios Andaluces, 213-319.

- (2013): «La enseñanza de la lengua en Andalucía y el andaluz en los medios de comunicación». En Antonio Narbona Jiménez (coord.), Conciencia y valoración del habla andaluza, Sevilla: Universidad Internacional de Andalucía, 257-329. <https://idus.us.es/xmlui/handle/11441/25173>. 
- (2019): «Posiciones enunciativas e ideología en los discursos metalingüísticos sobre la variedad andaluza en la prensa española. De 1977 a la actualidad». En Carmen Marimón Llorca e Isabel Santamaría Pérez (eds.), Ideologías sobre la lengua y medios de comunicación escritos. El caso del español, Berlín: Peter Lang, 193-215.

Morgenthaler García, Laura (2008): Identidad y pluricentrismo lingüistico: hablantes canarios frente a la estandarización, Madrid: Iberoamericana.

NARbona JimÉnez, Antonio (1998): «¿Normalizar el andaluz?», El Siglo que viene. Revista de Cultura, febrero 33, 18-22.

Ortega OJEDA, Gonzalo (1981): «El español hablado en Canarias: visión sociolingüística», Revista de Filología de la Universidad de La Laguna 0, 111-116.

Perona PÁez, Juan José (2009): «Información radiofónica y libros de estilo: análisis y propuestas de unos textos que claman renovación», Estudios sobre el Mensaje Periodístico 15, 367-384.

Rodero Antón, Emma (2003): Locución radiofónica, Salamanca: Universidad Pontificia.

Rojas Torrijos, José Luis (2011): Periodismo deportivo de calidad. Propuesta de libro de estilo panhispánico para informadores deportivos, Madrid: Fragua.

SÁNCHEZ ARNOSI, Milagros (1994): «Informe sobre los libros de estilo». En Actas del Congreso de la Lengua Española. Sevilla, 7 al 10 de octubre de 1992, Madrid: Instituto Cervantes, 79-83.

SANTANA Marrero, Juana (2018): «Creencias y actitudes de los jóvenes universitarios sevillanos hacia las variedades cultas del español», Boletín de Filología $53 / 2,115-144$.

TrujILLO, Ramón (1981): «Algunas características de las hablas canarias», Estudios Colombinos 2, 23-24.

Tubau, Iván (1995): Periodismo oral. Hablar y escribir para radio y televisión, Barcelona: Paidós.

UREÑA RodRíguez, Leticia (2014): «España contra Andalucía, o la vigencia mediática de ciertos tópicos lingüísticos». En Francisco Carriscondo Esquivel (ed. y coord.), La lengua en el candelero, Madrid: Academia del Hispanismo, 171-204.

- (2015): «Persistencia de ciertos tópicos sobre las hablas andaluzas en los medios de comunicación». En Francisco Carriscondo Esquivel (ed. y coord.), Asedios políticos a las lenguas desde los medios, Madrid: Academia del Hispanismo, 223-243.

VAz DE Soto, José Manuel (1981): Defensa del habla andaluza, Sevilla: EDISUR.

- (1995): Presente y futuro del habla andaluza, Huelva: Universidad de Huelva.

- (1998): «Pautas para locutores andaluces», El Siglo que viene. Revista de Cultura, febrero $33,42-45$.

\section{LIBROS DE ESTILO ANALIZADOS:}

Agencia Efe (1985): Manual de español urgente, Madrid: Cátedra.

Allas Llorente, José María y Luis Carlos Díaz SAlgado (coords.) (2004): Libro de estilo de Canal Sur Televisión y Canal 2 Andalucía, Sevilla: Canal Sur.

CADENA SER (2017): En Antena, libro de estilo del periodismo oral, Madrid: Taurus. 
CNN EN ESPAÑOL (2002): Manual de estilo y referencia de la CNN, 2. ${ }^{a}$ ed., Atlanta: CNN en español.

COPE (2003): El Libro de estilo COPE, Logroño: Cadena COPE.

Gómez Font, Alberto (ed.) (2003): Manual de estilo National Association of Hispanic Journalists, Washington, D. C.: Knight Ridder.

Hernández Hernández, Humberto (2004): El mensaje en los medios. A propósito del estudio lingüistico de la prensa regional canaria, Madrid: Iberoamericana Vervuert.

Hernández Hernández, Humberto (2009): Norma lingüistica y español de Canarias. Manual de consulta para periodistas, Santa Cruz de Tenerife: Gobierno de Canarias.

Madero, Félix et al. (1996): Guía de estilo de Onda Cero Radio, Madrid: Onda Cero. MENDIETA, Salvador (1993): Manual de estilo de TVE, Barcelona: Labor.

TELEMADRID (1993): Libro de estilo de Telemadrid, 2 vols., Madrid: Telemadrid. 